presented in separate chapters dealing with average household diets and expenditure, diet in different social classes, geographical differences, and special investigations concerned with matters such as the effect of the housewife's age and employment on the family's diet. There is no overall summary. The early chapters give an encouraging picture of general improvement, while some of the later ones deal with less-satisfactory aspects of the situation. But the facts are there, even though they may be overlooked by the casual reader.
Nutrition in Britain 1950-60 is of value in emphasizing that a complacent attitude towards national food consumption should be avoided, and also in analysing some of the technical difficulties in applying any dietary standard, as well as the defects of the British Medical Association standard itself. The future of Britain lies with its children, and we must be certain that they are properly fed. Any evidence that their diets are not fully satisfactory should be taken seriously and calls for further investigation.

Joyce DOUghTY

\title{
NOCTULE BATS FEEDING ON COCKCHAFERS
}

$\mathrm{N}$ OCTULE bats usually hunt their prey at tree-top height, with a rapid, powerful flight, though they have been recorded as flying low to take cockchafers. Cockchafers only fly over a short period, and the combination of the flight of cockchafers, noctule bats and observer occurs too seldom.

In 1960 the Earl of Cranbrook found noctules and serotines (Eptesicus serotinus) hunting summer chafers (Amphimallus solstitialis) and watched them on three successive evenings*. For most of the time the bats flew up and down, parallel to and a few yards from the hedge in which the chafers were crawling, seizing them as they flew from the twigs into the open. At fairly frequent intervals a chafer would make a loud buzzing noise from inside the hedge, as if it were caught up in some obstruction. If this noise lasted more than five seconds or so it almost invariably brought a bat so close to the hedge that it seemed to be picking up its prey from among the twigs. On no occasion was a bat actually seen to pick a chafer from the hedge, but they were obviously attracted by the 'loud buzzing' ones.

H. G. Barnett and the Earl of Cranbrook were able to watch noctules catching June bugs flying in and about some oak trees standing in the park and garden of Great 1964).

* Transactions of the Suffolk Naturalists' Society, 12, Part 5 (January,
Glemham House for ten days in 1963. Usually, on any fine night in summer, they can be seen hawking their prey in the normal way at tree-top height, when they are easily seen against the sky. An exact count is impossible: the bats are not concentrated but diffused as individuals over a wide area. On a normal night, about six to a dozen noctules can be seen hunting over an area of about ten acres.

When hunting cockchafers they were much more concentrated, presumably because their prey, too, was concentratod. Over a small area of about a couple of acres a score or more noctules hunted each night, showing remarkable control and manœuvrability at low speeds. In general, the bats circled around among the trees, picking up the cockchafers as they flew out, but frequently a bat would be seen to fly right into the open spaces among the branches. At times the bats would slow down to pick up a cockchafer as it flew from the twigs, sometimes hovering with rapidly beating wings, sometimes stopping abruptly, the wings rigid and outstretched with the body held almost vertical. The bats took cockchafers at all heights, not infrequently flying below lower branches to pick up insects as they fell from above.

The report also describes observations with noctules and house-crickets.

\section{CURVATURE IN THE SPECTRA OF NON-THERMAL RADIO SOURCES}

\author{
By Dr. WILLIAM E. HOWARD, III, TOM R. DENNIS, STEPHEN P. MARAN \\ and HUGH D. ALLER \\ Department of Astronomy, University of Michigan, Ann Arbor
}

\begin{abstract}
A CATALOGUE of the available observational data on about 1,260 discrete radio sources has been prepared at this Observatory and will be submitted for publication shortly. A well-known difficulty in analysing flux density data is that systematic differences may exist between the measurements made by various workers, due to the different techniques of calibration and to the variety of equipments and observational procedures that have been employed. We report here some preliminary results on the spectra of extragalactic radio sources, primarily in the frequency range $38-3,200 \mathrm{Mc} / \mathrm{s}$, which have been made possible by the determination of the necessary systematic corrections to various radio astronomy surveys, with respect to a uniform scale of flux density based on 148 small-diameter sources. For all but two of these sources, nine or more measurements of flux density at different frequencies were used. On Cygnus $A$, the best-observed source, 63 observations were included in the solution.
\end{abstract}

The flux density system, the systematic errors of the surveys and the parameters of each radio source were determined by the following procedure, using the IBM
7090 in the University of Michigan Computing Center. First, two unweighted least-squares solutions were made for each of the 148 sources to find the parameters in the following equations:

$$
\begin{gathered}
\log S_{v}=a_{0}+b_{0} \log \nu \\
\log S_{v}=a+b \log v+c(\log v)^{2}
\end{gathered}
$$

where $S_{v}$ is the flux density in units of $10^{-26} \mathrm{~W} \mathrm{~m}^{-2}(\mathrm{c} / \mathrm{s})^{-1}$ and $\nu$ is the frequency in Me/s. Next, Gauss's criterion was used to determine which equation gave statistically the best fit to the data, allowing for the fact that (2) has an additional degree of freedom to be considered. Then the systematic errors of each of the surveys were determined from the deviations of the points from the optimum equations and the standard deviation of a single observa. tion $(\sigma)$ was found for each survey. Each of the input observations was weighted by $1 / \sigma^{2}$ and a weighted set of coefficients and systematic survey errors were computed. The input observations were corrected by the appropriate systematic errors, and the general iterative procedure was repeated four times. The procedure was tested for convergence and was found to be stable. Between the third 